\title{
Risk Factors for Seizures after Hematopoietic Stem Cell Transplantation in Pediatric Hemato-Oncologic Patients: A Single Tertiary Center Study in the Republic of Korea
}

\author{
Ja Un Moon, MD, Joo Young Lee, MD, Jae Wook Lee, MD, Nack Gyun Chung, MD, Bin Cho, MD, In Goo Lee, MD \\ Division of Neurology, Department of Pediatrics, College of Medicine, The Catholic University of Korea, Seoul, Korea
}

Received: March 17, 2021

Revised: April 8, 2021

Accepted: April 8, 2021

Corresponding author:

In Goo Lee, MD

Division of Neurology, Department

of Pediatrics, College of Medicine,

The Catholic University of Korea,

222 Banpo-daero, Seocho-gu,

Seoul 06591, Korea

Tel: +82-2-2258-6186

Fax: +82-2-537-4544

E-mail: iglee@catholic.ac.kr
Purpose: The aim of this study was to assess the incidence of seizures, clinical manifestations, and risk factors that could predict the occurrence of seizures after hematopoietic stem cell transplantation (HSCT) in children.

Methods: The study group consisted of 543 patients (311 males and 232 females) registered at the Catholic University of Korea's Seoul St. Mary's Hospital who received HSCT before the age of 18 from January 2009 to January 2019. Their medical records and test results were retrospectively reviewed.

Results: The incidence of seizure after HSCT was $6.6 \%$ and the average age of seizure patients was $8.33 \pm 5.5$ years. The use of calcineurin inhibitors combined with methotrexate as prophylaxis for graft versus host disease (GVHD) was a statistically significant risk factor for seizures $(P=0.006)$. Pediatric patients with grade $2-4$ acute GVHD $(P=0.003)$ also showed a higher incidence of seizures than those with grade $0-1$ acute GVHD after HSCT.

Conclusion: Our findings indicate that among pediatric patients who underwent HSCT, using calcineurin inhibitors with methotrexate as a conditioning regimen and a higher grade $(\geq 2)$ of acute GVHD are risk factors of seizures.

Keywords: Neurologic manifestations; Seizures; Hematopoietic stem cell transplantation; Risk factors

\section{Introduction}

Hematopoietic stem cell transplantation (HSCT) is widely used as a complete cure for patients with reduced bone marrow function due to various malignancies (such as leukemia, malignant lympho$\mathrm{ma}$, and solid neoplasms) and some nonmalignant conditions (such as severe aplastic anemia, sickle cell disease, thalassemia, immune disorders, certain metabolic disorders, and severe refractory autoimmune diseases) [1]. The HSCT procedure consists of in- fusing hematopoietic stem cells after a short course of high-dose chemotherapy that is frequently associated with total body irradiation (TBI) to suppress the host immune system in order to prevent graft rejection. HSCT often places patients at risk of life-threatening complications throughout the course of treatment and beyond. Despite significant improvements in peri-transplant treatment, neurological complications-especially those involving the central nervous system (CNS) - along with many other complications, such as graft rejection or graft failure, thrombocytopenia, metabol-

Copyright @ 2021 Korean Child Neurology Society

This is an Open Access article distributed under the terms of the Creative Commons Attribution Non-Commercial License (http://creativecommons.org/licenses/by-nc/4.0/) which permits unrestricted non-commercial use, distribution, and reproduction in any medium, provided the original work is properly cited. 
ic disturbances, chemotherapy/radiotherapy-induced toxicity, infection, and graft versus host disease (GVHD), remain contributors to morbidity and mortality during the post-HSCT period [24]. The total incidence of neurological complications after HSCT has been reported to range from $8 \%$ to $70 \%[5,6]$. Seizure is the most common clinical manifestation of neurological complications $[7,8]$, and younger people have a higher risk of seizures than adults after HSCT [9]. However, only a few studies have analyzed differences between patients with seizures and those without seizures and risk factors for seizures after HSCT, especially in the pediatric population. The aim of this study was to evaluate the frequency, clinical features, and risk factors of seizures to identify information that could be used to prevent seizures and improve the prognosis of pediatric patients after HSCT.

\section{Materials and Methods}

\section{Patients}

The study group consisted of 543 patients ( 311 males and 232 females) registered at the Catholic University of Korea's Seoul St. Mary's Hospital who received allogeneic (506 patients) or autologous (37 patients) HSCT before the age of 18 as treatment for malignancies or other non-malignant hematologic diseases from January 2009 to January 2019.

We retrospectively reviewed the records of all patients who underwent at least one neurological diagnostic test, including brain magnetic resonance imaging (MRI) and electroencephalography (EEG), after HSCT. We also reviewed records of demographic characteristics, including patients' age, sex, underlying disease, type of HSCT, conditioning regimen (including TBI, busulfan administration, or both), and grade of acute GVHD. The diagnosis of acute GVHD was based on the Glucksberg Seattle criteria [10]. Patients were divided into those younger than 5 years and older than 5 years based on the age at the time of HSCT. This study group was monitored for at least 6 months. Among the 36 patients who experienced seizures, seven patients with a preexisting history of seizures before HSCT were excluded from this study.

\section{Type of HSCT}

HSCT procedures can be classified into two types: (1) allogeneic HSCT, which uses hematopoietic stem cells harvested from a donor; and (2) autologous HSCT, which uses hematopoietic stem cells harvested from the patient's bone marrow or peripheral blood.

\section{Conditioning regimen}

All patients received pre-transplantation conditioning treatment based on the underlying disease according to the transplant pro- gram protocol. In this study, we divided the type of conditioning regimen as follows, regardless of overall intensity: TBI-based, busulfan-based, TBI and busulfan-based, and others.

\section{Prophylaxis for GVHD}

As prophylaxis for GVHD, calcineurin inhibitors (cyclosporine, tacrolimus) with or without methotrexate (MTX), antithymoglobulin, and a steroid were administered according to the institutional protocol.

\section{Clinical profiles of seizures}

The diagnosis of seizures was based on clinical manifestations and neurological/physical examination findings, laboratory findings, EEG findings, and brain MRI conducted at the time of the seizures. Seizure types were classified according to the 2017 International League against Epilepsy criteria. The timing of seizures was classified into three categories according to three phases of immune status, since the timing of neurological complications is similar to the timing of complications in other organs associated with the three phases of patient's immune status after HSCT: (1) the pre-engraftment period ( $<30$ days post-HSCT); (2) the early post-engraftment period ( 30 to 100 days post-HSCT); and (3) the later post-engraftment period ( $>100$ days post-HSCT) [11]. Abnormalities on EEG included background abnormalities and abnormal epileptiform discharges. Epileptiform discharges were divided into focal and generalized depending on the region of the epileptic focus. The outcome of seizures included freedom from seizures, development of epilepsy, and death. Freedom from seizures was defined as a sustained seizure-free status for at least 12 months.

\section{Statistical methods}

Patients were classified into those with seizures and those without seizures. SSPS software version 24.0 (IBM Corp., Armonk, NY, USA) was used for all statistical analyses. Normally distributed variables are presented as mean \pm standard deviation. Univariate analysis was carried out to compare independent variables as risk factors for seizure after HSCT using the chi-square test. Statistically significant variables $(P<0.05)$ in the univariate analysis were included in the multivariate logistic regression analysis.

\section{Results}

\section{Characteristics of patients after HSCT}

A total of 543 patients underwent HSCT, including 370 patients (69.3\%) who had malignant diseases such as leukemia, lymphoma, and solid neoplasms and 173 patients (32.4\%) who had non-ma- 
lignant hematologic diseases (Table 1). A total of 506 patients received allogeneic HSCT and 37 received autologous HSCT. The average age of the patients was $8.88 \pm 5.5$ years (range, 5 months to 18 years). There were $162(29.8 \%)$ patients who were younger than 5 years and $381(70.2 \%)$ patients who were older than 5 years (Table 1).

There were 138 patients (25.4\%) who received TBI-based conditioning regimens for HSCT, 210 patients (38.7\%) who received busulfan-based regimens, 45 patients $(8.3 \%)$ who received both TBI- and busulfan-based regimens, and 150 patients (27.6\%) who received other regimens. For GVHD prophylaxis, 311 patients (57.3\%) received calcineurin inhibitors, 62 patients (11.4\%) received MTX, 138 patients (25.4\%) received calcineurin inhibitors combined with MTX, and 32 patients (5.9\%) received other immunosuppressants (Table 1).

\section{Clinical characteristics of seizures after HSCT}

HSCT-associated seizures were observed in 36 of the 543 pediatric patients (Table 2). The incidence of seizures after HSCT was $6.6 \%$. The average age of the seizure patients was $8.33 \pm 5.5$ years. The ratio of male to female patients was 1.25:1 (20:16). The clinical characteristics of post-HSCT seizures are described in Table 2. Seizures were observed between 3 days and 18 months after HSCT, with nine patients (25.0\%) having seizures within the pre-engraftment period, 13 patients (36.1\%) having seizures between 30 and 100 days, and 14 patients (38.9\%) having seizures after 100 days postHSCT (Table 2). Generalized seizures were observed in 24 patients (66.7\%), whereas focal seizures were observed in 12 patients (33.3\%). Of the 36 patients who developed seizures, two patients did not undergo brain MRI due to unstable vital signs. Of the remaining 34 patients who underwent brain MRI, eight (23.6\%) had normal results and 26 (76.4\%) had abnormal results.

Table 1. Comparision of characteristics between patients with and without seizures after hematopoietic stem cell transplantation

\begin{tabular}{|c|c|c|}
\hline Characteristic & With seizures $(n=36,6.6 \%)$ & Without seizures $(n=507,93.3 \%)$ \\
\hline Age (yr) & $8.33 \pm 5.54$ & $9.33 \pm 5.62$ \\
\hline $0-5$ & $9(25.0)$ & $153(30.1)$ \\
\hline$>5$ & $27(75.0)$ & $354(69.9)$ \\
\hline \multicolumn{3}{|l|}{ Sex } \\
\hline Male & $20(55.0)$ & $291(57.4)$ \\
\hline Female & $16(45.0)$ & $216(42.6)$ \\
\hline \multicolumn{3}{|l|}{ Conditioning regimen } \\
\hline TBI-based & $12(33.3)$ & $126(24.9)$ \\
\hline Busulfan-based & $13(36.1)$ & $197(38.9)$ \\
\hline TBI+Busulfan-based & $2(5.6)$ & $43(8.5)$ \\
\hline Others $^{\mathrm{a}}$ & $9(25.0)$ & $141(27.8)$ \\
\hline \multicolumn{3}{|l|}{ GVHD prophylaxis } \\
\hline Calcineurin inhibitors ${ }^{\mathrm{b}}$ & 17 (47.2) & $294(57.9)$ \\
\hline MTX & 4 (11.1) & $58(11.5)$ \\
\hline Calcineurin inhibitors $+\mathrm{MTX}$ & $13(36.1)$ & $125(24.6)$ \\
\hline Others ${ }^{c}$ & $2(5.6)$ & $30(6.0)$ \\
\hline \multicolumn{3}{|l|}{ Type of HSCT } \\
\hline Autologous & $2(5.56)$ & $35(7.0)$ \\
\hline Allogeneic & $34(94.4)$ & $472(93.0)$ \\
\hline \multicolumn{3}{|l|}{ aGVHD grade } \\
\hline $0-1$ & 19 (52.8) & 365 (71.9) \\
\hline $2-4$ & $17(47.2)$ & $142(28.1)$ \\
\hline \multicolumn{3}{|l|}{ Disease } \\
\hline Malignant & $24(66.7)$ & $346(68.2)$ \\
\hline Non-malignant & $12(33.3)$ & $161(31.8)$ \\
\hline
\end{tabular}

Values are presented as mean \pm standard deviation or number $(\%)$.

TBI, total body irradiation; GVHD, graft versus host disease; MTX, methotrexate; HSCT, hematopoietic stem cell transplantation; aGVHD, acute graft versus host disease.

${ }^{a}$ Conditioning regimen without busulfan and total body irradiation; ${ }^{b}$ Calcineurin inhibitors included cyclosporine and tacrolimus; ${ }^{\mathrm{C} S t e r o i d} \pm$ antithymoglobulin administrated as a prophylaxis. 
Table 2. Clinical profiles of seizures after hematopoietic stem cell transplantation

\begin{tabular}{lc}
\hline Variable & No. (\%) \\
\hline Seizure onset (post HCST) & 36 \\
$<30$ days & $9(25.0)$ \\
$30-100$ days & $13(36.1)$ \\
$>100$ days & $14(38.9)$ \\
Seizure type & 36 \\
Generalized & $24(66.7)$ \\
Focal & $12(33.3)$ \\
Brain MRI findings & 34 \\
Normal & $8(23.6)$ \\
Abnormal & $26(76.4)$ \\
PRES & $13(50.0)$ \\
Cortical ischemia & $1(3.8)$ \\
Intracranial hemorrhage & $4(15.4)$ \\
Malignant brain lesion & \\
CNS infection & $3(11.5)$ \\
EEG & $5(19.2)$ \\
Normal & 32 \\
Abnormal & \\
Outcome & $6(16.7)$ \\
Freedom from seizures & \\
Development of epilepsy & $26(81.3)$ \\
Death & $26(72.2)$ \\
\hline
\end{tabular}

HSCT, hematopoietic stem cell transplantation; MRI, magnetic resonance imaging; PRES, posterior reversible encephalopathy syndrome; CNS, central nervous system; EEG, electroencephalography.

${ }^{a}$ Malignant brain lesions included a relapse or metastasis to the brain of original malignancies such as leukemia and lymphoma; ${ }^{b}$ Abnormalities in electroencephalography included background abnormalities and abnormal

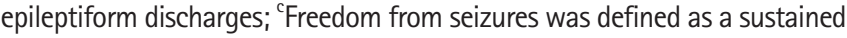
seizure-free status for at least 12 months.

Sepsis, cytomegalovirus meningitis, and metabolic imbalances including hyponatremia ( $<135 \mathrm{mM})$, hypokalemia $(<3.5 \mathrm{mM})$, and abnormal liver function were observed in patients who showed normal brain MRI. The most frequent abnormal brain MRI finding was posterior reversible encephalopathy syndrome (PRES; $n=13,50.0 \%)$, followed by CNS infection $(n=5,19.2 \%)$. Intracranial hemorrhage and cortical ischemia were present in four patients and one patient, respectively. Malignant brain lesions reflecting CNS involvement, including relapse or metastasis of original malignancies, were observed in three patients, and were also confirmed by a cerebrospinal fluid test. Post-ictal EEG was performed in 32 patients, of whom 26 (81.3\%) had abnormal EEG results. Seventeen patients $(65.4 \%)$ showed background abnormalities with diffuse slow waves, and nine patients (34.6\%) had epileptiform discharges, including eight patients (30.8\%) who showed focal epileptiform discharges and one patient (3.8\%) who showed generalized epileptiform discharges.

Twenty-six of the seizure patients became seizure-free (72.2\%) without requiring antiepileptic drugs, whereas six patients developed epilepsy and four patients died during follow-up.

\section{Statistical analysis of seizures and risk factors}

To analyze risk factors for developing seizures in HSCT patients, patients' age at the time of seizures, sex, conditioning regimen, prophylaxis for GVHD, type of HSCT (allogeneic or autologous), grade of acute GVHD, and underlying disease were considered. The results of the univariate and multivariate analyses of significant risk factors are shown in Table 3.

\section{1) Prophylaxis for GVHD}

Of 449 patients who received a calcineurin inhibitor with or without other regimens as prophylaxis for GVHD, 30 (6.7\%) developed seizures. In the univariate analysis, patients with calcineurin inhibitors alone were found to be more likely to have seizures $(P=0.046)$ than those who received GVHD prophylaxis without calcineurin inhibitors alone, whereas multivariate analysis showed no significant difference in the risk of developing seizures between the two groups. However, patients using calcineurin inhibitors combined with MTX showed a higher risk of developing seizures than patients with other prophylaxis regimens $(P=0.006)$.

\section{2) Grade of acute GVHD}

Among patients with acute GVHD, 19 (4.9\%) out of 384 patients with grade $0-1$ and 17 (10.7\%) out of 159 patients with grade 2-4 developed seizures. Those with grade $2-4$ acute GVHD had a higher risk of developing seizures than those with grade $0-1$ acute GVHD $(P=0.010)$. In the multivariate analysis, grade $2-4$ acute GVHD remained a significant risk factor for seizures $(P=0.003)$.

\section{Discussion}

Neurological complications associated with HSCT are important causes of morbidity and mortality in both children and adults. Most neurological complications are caused by the original disease or relapse, development of a secondary tumor, treatment-induced neurotoxicity including chemotherapy and TBI, CNS infection, cerebrovascular disease, and metabolic encephalopathy $[6,9,12$, 13]. In our study, the incidence of seizures in children after HSCT was $6.6 \%$, which is slightly lower than the incidence that we reported in the past (13.8\%) [14]. This might be attributable to the improved treatment environment including prompt diagnosis and advanced prophylaxis/treatment of HSCT, including strictly controlled blood pressure and dose reduction or switching between 
Table 3. Univariate and multivariate analysis of risk factors for seizures after hematopoietic stem cell transplantation

\begin{tabular}{|c|c|c|c|c|c|}
\hline \multirow{2}{*}{ Variable } & \multirow{2}{*}{ No. } & \multicolumn{2}{|c|}{ Univariate analysis } & \multicolumn{2}{|c|}{ Multivariate analysis } \\
\hline & & OR (95\% Cl) & $P$ value & OR (95\% Cl) & $P$ value \\
\hline \multicolumn{6}{|l|}{ Age, mean (yr) } \\
\hline $0-5$ & 162 & $2.4(1.16-5.84)$ & 0.517 & & \\
\hline$>5$ & 381 & & & & \\
\hline \multicolumn{6}{|l|}{ Sex } \\
\hline Male & 311 & $1.2(0.61-4.32)$ & 0.732 & & \\
\hline Female & 232 & & & & \\
\hline \multicolumn{6}{|l|}{ TBI alone } \\
\hline Yes & 138 & $2.1(0.95-5.27)$ & 0.337 & & \\
\hline No & 405 & & & & \\
\hline \multicolumn{6}{|l|}{ Busulfan alone } \\
\hline Yes & 210 & $3.7(1.44-9.41)$ & 0.594 & & \\
\hline No & 333 & & & & \\
\hline \multicolumn{6}{|l|}{ TBI+Busulfan } \\
\hline Yes & 45 & $1.5(0.671-4.22)$ & 0.411 & & \\
\hline No & 498 & & & & \\
\hline \multicolumn{6}{|c|}{ Calcineurin inhibitor alone } \\
\hline Yes & 311 & $4.5(1.81-11.39)$ & 0.046 & $3.1(1.57-13.67)$ & 0.071 \\
\hline No & 232 & & & & \\
\hline \multicolumn{6}{|l|}{ MTX alone } \\
\hline Yes & 62 & $2.2(1.05-6.14)$ & 0.541 & & \\
\hline No & 481 & & & & \\
\hline \multicolumn{6}{|c|}{ Calcineurin inhibitor ${ }^{\mathrm{a}}+\mathrm{MTX}$} \\
\hline Yes & 138 & $3.4(0.79-7.23)$ & 0.033 & $11.4(2.7-54.2)$ & 0.006 \\
\hline No & 405 & & & & \\
\hline \multicolumn{6}{|l|}{ Type of HSCT } \\
\hline Autologous & 37 & $1.4(0.58-4.71)$ & 0.521 & & \\
\hline Allogeneic & 506 & & & & \\
\hline \multicolumn{6}{|l|}{ aGVHD grade } \\
\hline $0-1$ & 384 & $2.1(1.17-4.87)$ & 0.010 & $9.7(1.08-63.3)$ & 0.003 \\
\hline $2-4$ & 159 & & & & \\
\hline \multicolumn{6}{|l|}{ Disease } \\
\hline Malignant & 370 & $1.2(0.76-3.21)$ & 0.848 & & \\
\hline Non-malignant ${ }^{b}$ & 173 & & & & \\
\hline
\end{tabular}

$\mathrm{OR}$, odds ratio; $\mathrm{Cl}$, confidence interval; $\mathrm{TB}$, total body irradiation; $\mathrm{MTX}$, methotrexate; $\mathrm{HSCT}$, hematopoietic stem cell transplantation; aGVHD, acute graft versus host disease.

${ }^{a}$ Calcineurin inhibitors included cyclosporine and tacrolimus; ${ }^{b}$ Non-maglinant conditions included severe aplastic anemia, sickle cell disease, thalassemia, and immune disorders.

calcineurin inhibitors to reduce drug-induced neurotoxicity. According to other studies, the incidence of seizures among HSCT patients varies from $1.6 \%$ to $15.4 \%[9,12]$. This variability might be due to differences in patients, transplantation characteristics, duration of follow-up, and trial design.

Previous studies have identified high doses of TBI and chemotherapy (including calcineurin inhibitors, busulfan, and MTX) as risk factors for seizures after HSCT $[15,16]$. Calcineurin inhibitors (cyclosporine and tacrolimus) are commonly used immunosup- pressants. They work by inhibiting T-lymphocyte activation and proliferation, but might increase the permeability of the bloodbrain barrier (BBB), resulting in neurotoxicity [17]. In vitro and in vivo studies have reported that vasoconstrictive effects via activation of sympathetic outflow by calcineurin inhibitors might also increase the permeability of the BBB $[17,18]$. Comorbid conditions, including hypertension, infection, and metabolic disorders such as hypomagnesemia, might further exacerbate the permeability of the BBB $[19,20]$. Furthermore, calcineurin inhibitors may 
modulate neuronal excitation and neuronal inhibition (known to play an important role in seizures) by altering gamma-aminobutyric acid (GABA) and N-methyl-D-aspartic acid (NMDA)-mediated responses via calcineurin [21]. The incidence of seizures caused by calcineurin inhibitors is generally less than $1 \%$, although a previous study reported an incidence as high as 14.8\% [22]. Although our results showed that the use of calcineurin inhibitors alone was not a statistically significant risk factor for seizure development, the fact that calcineurin inhibitor use combined with MTX did show statistical significance implicates calcineurin inhibitors as a risk factor for the development of seizures. A previous study also showed that calcineurin inhibitors, especially cyclosporine, combined with MTX in the regimen for prophylaxis of GVHD were a risk factor for seizures after HSCT [23], suggesting that cumulative exposure to immunosuppressants might exacerbate drug-induced neurotoxicity and susceptibility to CNS infection, thereby increasing the incidence of seizures.

Busulfan is frequently used in conditioning regimens for HSCT. It has therapeutic effects on the CNS, and it crosses the BBB freely [24]. However, it may cause neurotoxicity and result in seizures. The incidence of seizures in those who have received busulfan after HSCT ranges from $10 \%$ to $40 \%$ if anticonvulsants are not given [25]. In our study, 15 (5.9\%) out of 255 patients who were administered busulfan in the conditioning regimen had seizures. However, none of them had seizures during the pre-treatment period for HSCT, possibly due to co-administration of phenytoin, which might have prevented busulfan-induced seizures.

During the pre-engraftment period (days 0-30), the patient's immune system is completely suppressed. Due to high-dose chemotherapy with or without TBI as a result of the conditioning regimen for HSCT, the patient is vulnerable to severe infections [23]. In the early post-engraftment period (days 30-100), the patient's immune system starts to recover. Acute GVHD may develop in this period. By 100 days after HSCT, the patient's immune system continues to recover gradually, moving towards full recovery. Chronic GVHD may develop $[11,26]$. Our results showed that, by a narrow margin, the emergence of seizures mostly occurred after 100 days of HSCT. In the post-transplantation period, especially at 3 months after HSCT and beyond, an increased concentration of immunosuppressants (e.g., cyclosporine and corticosteroids) administered as prophylaxis/treatment for chronic GVHD can result in neurological complications [15], which may lead to the development of seizures.

We found that $83.3 \%(n=26)$ of all seizure patients had abnormalities on brain MRI, with PRES ( $n=13,50.0 \%)$ being the most frequent abnormal finding. PRES has been reported to be one of the most common encephalopathies that contribute to the occur- rence of seizures after transplantation $[27,28]$. The etiologies of PRES include hypertensive encephalopathy and treatment-related leukoencephalopathy, associated with both cranial irradiation and chemotherapy. Among 36 patients who experienced seizures in our study, 23 received cyclosporine to prevent and treat GVHD, and 17 of them showed a high blood concentration of cyclosporine ( $>250 \mathrm{ng} / \mathrm{mL}$ ). Although the pathophysiology of PRES is not fully understood [29] cyclosporine-associated PRES has been related to high levels of cyclosporine [27]. In addition, 29 patients with seizures received corticosteroids for GVHD treatment, which is relevant because corticosteroids can alter cyclosporine levels, potentially leading to the development of neurological complications [30]. Twenty-four patients showed increased blood pressure during seizures, whereas 12 patients had stable vital signs. The patients with hypertension were also being treated with immunosuppressants (cyclosporine and corticosteroids), which are known to cause high blood pressure $[19,29]$.

PRES can affect the white matter, particularly the subcortical white matter [31]. Although PRES is reversible and generally has a good prognosis, it can lead to permanent neurological deficits and an increased risk of mortality $[23,32]$. Furthermore, PRES seems to be associated with epilepsy diagnosis as a long-term consequence [33]. In our study, more than half of the patients (72.2\%) who experienced seizures were seizure-free, and most of them only had a single seizure, whereas only a minority of patients needed prolonged antiepileptic drug therapy. Most patients had a favorable prognosis; however, in patients with some conditions (especially CNS infection and intracranial hemorrhage), recurrent seizures occurred.

In a prior study based on serial EEG examinations, more than $80 \%$ of children who experienced seizures after HSCT showed diffuse slow waves of background activity [16]. Other studies have found focal and generalized slow activity consistent with encephalopathy based on post-ictal EEG obtained in the first 48 hours after the first seizures in HSCT patients [34]. In our data, $81.3 \%$ of patients who developed seizures had abnormalities on post-ictal EEG and more than half of them showed slow background activity, suggesting cerebral dysfunction. This shows that EEG might be a helpful tool for detecting abnormalities in brain function (e.g., encephalopathy) in HSCT patients, especially in children with seizures.

In addition to the use of calcineurin inhibitors with MTX for GVHD prophylaxis, another independent risk factor identified by multivariate statistical analysis for developing seizures in this study was high-grade (> grade 2) acute GVHD, similar to the findings reported in other studies [9,34-36]. As a possible explanation, prolonged and increased doses of immunosuppression to control se- 
vere GVHD might have resulted in high susceptibility to CNS infection and drug-induced neurotoxicity, thereby contributing to seizures [37]. Although acute GVHD greater than grade 2 has been reported to cause neurological complications $[16,35,36]$, little is known about its CNS involvement. Some animal studies support the likelihood of the brain being targeted for GVHD development due to increased expression of immune mediators in the brain parenchyma and cerebral vessels during GVHD [38]. Some clinical trials have also revealed the possibility of CNS involvement in GVHD by presenting inflammation in the brain without evidence of apparent infection [39].

In summary, in pediatric patients receiving HSCT for any reason, especially in patients receiving calcineurin inhibitors with MTX for GVHD prophylaxis and those with a higher grade $(\geq 2)$ of acute GVHD with a high risk of seizures, close observation and intensive care seem to be necessary to improve clinical outcomes.

The limitations of our research include its retrospective design and the small number of subjects. Thus, more studies are needed in the future to confirm our findings.

\section{Conflicts of interest}

No potential conflict of interest relevant to this article was reported.

\section{ORCID}

Ja Un Moon, https://orcid.org/0000-0002-9942-4609

In Goo Lee, https://orcid.org/0000-0001-8678-4050

\section{Author contribution}

Conceptualization: JUM, JYL, JWL, NGC, BC, and IGL. Data curation: JUM. Formal analysis: JUM, JWL, NGC, BC, and IGL. Methodology: JUM. Writing-original draft: JUM. Writing-review \& editing: JUM, JWL, and IGL.

\section{Acknowledgements}

This study was supported by the Seoul St. Mary Hospital of Catholic University of Korea.

\section{References}

1. Thomas ED, Lochte HL Jr, Lu WC, Ferrebee JW. Intravenous infusion of bone marrow in patients receiving radiation and chemotherapy. N Engl J Med 1957;257:491-6.

2. Maffini E, Festuccia M, Brunello L, Boccadoro M, Giaccone L, Bruno B. Neurologic complications after allogeneic hematopoietic stem cell transplantation. Biol Blood Marrow Transplant 2017;23:388-97.

3. Pruitt AA, Graus F, Rosenfeld MR. Neurological complications of transplantation: part I: hematopoietic cell transplantation. Neurohospitalist 2013;3:24-38.

4. Nishiguchi T, Mochizuki K, Shakudo M, Takeshita T, Hino M, Inoue Y. CNS complications of hematopoietic stem cell transplantation. AJR Am J Roentgenol 2009; 192:1003-11.

5. Graus F, Saiz A, Sierra J, Arbaiza D, Rovira M, Carreras E, et al. Neurologic complications of autologous and allogeneic bone marrow transplantation in patients with leukemia: a comparative study. Neurology 1996;46:1004-9.

6. de Brabander C, Cornelissen J, Smitt PA, Vecht CJ, van den Bent MJ. Increased incidence of neurological complications in patients receiving an allogenic bone marrow transplantation from alternative donors. J Neurol Neurosurg Psychiatry 2000;68:36-40.

7. Soni S, Skeens M, Termuhlen AM, Bajwa RP, Gross TG, Pai V. Levetiracetam for busulfan-induced seizure prophylaxis in children undergoing hematopoietic stem cell transplantation. Pediatr Blood Cancer 2012;59:762-4.

8. Kang JM, Kim YJ, Kim JY, Cho EJ, Lee JH, Lee MH, et al. Neurologic complications after allogeneic hematopoietic stem cell transplantation in children: analysis of prognostic factors. Biol Blood Marrow Transplant 2015;21:1091-8.

9. Zhang XH, Xu LP, Liu DH, Chen H, Han W, Chen YH, et al. Epileptic seizures in patients following allogeneic hematopoietic stem cell transplantation: a retrospective analysis of incidence, risk factors, and survival rates. Clin Transplant 2013;27:80-9.

10. Glucksberg H, Storb R, Fefer A, Buckner CD, Neiman PE, Clift $\mathrm{RA}$, et al. Clinical manifestations of graft-versus-host disease in human recipients of marrow from HL-A-matched sibling donors. Transplantation 1974;18:295-304.

11. Dykewicz CA; Centers for Disease Control and Prevention (U.S.); Infectious Diseases Society of America; American Society of Blood and Marrow Transplantation. Summary of the guidelines for preventing opportunistic infections among hematopoietic stem cell transplant recipients. Clin Infect Dis 2001;33:139-44.

12. Kishi Y, Miyakoshi S, Kami M, Ikeda M, Katayama Y, Murashige $\mathrm{N}$, et al. Early central nervous system complications after reduced-intensity stem cell transplantation. Biol Blood Marrow Transplant 2004;10:561-8.

13. Antonini G, Ceschin V, Morino S, Fiorelli M, Gragnani F, Men- 
garelli A, et al. Early neurologic complications following allogeneic bone marrow transplant for leukemia: a prospective study. Neurology 1998;50:1441-5.

14. Chung NY, Lee JW, Lee DH, Cho B, Choi BJ, Kim YH, et al. The clinical manifestations and the risk factors of seizures after hematopoietic stem cell transplantation in children. J Korean Child Neurol Soc 2006; 14:266-75.

15. Yoshida S, Hayakawa K, Yamamoto A, Kuroda H, Imashuku S. The central nervous system complications of bone marrow transplantation in children. Eur Radiol 2008;18:2048-59.

16. Faraci M, Lanino E, Dini G, Fondelli MP, Morreale G, Dallorso $\mathrm{S}$, et al. Severe neurologic complications after hematopoietic stem cell transplantation in children. Neurology 2002;59:1895904.

17. Kochi S, Takanaga H, Matsuo H, Ohtani H, Naito M, Tsuruo T, et al. Induction of apoptosis in mouse brain capillary endothelial cells by cyclosporin A and tacrolimus. Life Sci 2000;66:225560.

18. Lyson T, Ermel LD, Belshaw PJ, Alberg DG, Schreiber SL, Victor RG. Cyclosporine- and FK506-induced sympathetic activation correlates with calcineurin-mediated inhibition of T-cell signaling. Circ Res 1993;73:596-602.

19. Schwartz RB, Bravo SM, Klufas RA, Hsu L, Barnes PD, Robson $\mathrm{CD}$, et al. Cyclosporine neurotoxicity and its relationship to hypertensive encephalopathy: CT and MR findings in 16 cases. AJR Am J Roentgenol 1995; 165:627-31.

20. Woo M, Przepiorka D, Ippoliti C, Warkentin D, Khouri I, Fritsche $\mathrm{H}$, et al. Toxicities of tacrolimus and cyclosporin A after allogeneic blood stem cell transplantation. Bone Marrow Transplant 1997;20:1095-8.

21. Shuto H, Kataoka Y, Fujisaki K, Nakao T, Sueyasu M, Miura I, et al. Inhibition of GABA system involved in cyclosporine-induced convulsions. Life Sci 1999;65:879-87.

22. Eidelman BH, Abu-Elmagd K, Wilson J, Fung JJ, Alessiani M, Jain A, et al. Neurologic complications of FK 506. Transplant Proc 1991;23:3175-8.

23. Siegal D, Keller A, Xu W, Bhuta S, Kim DH, Kuruvilla J, et al. Central nervous system complications after allogeneic hematopoietic stem cell transplantation: incidence, manifestations, and clinical significance. Biol Blood Marrow Transplant 2007;13: 1369-79.

24. Meloni G, Raucci U, Pinto RM, Spalice A, Vignetti M, Iannetti P. Pretransplant conditioning with busulfan and cyclophosphamide in acute leukemia patients: neurological and electroencephalographic prospective study. Ann Oncol 1992;3:145-8.

25. Eberly AL, Anderson GD, Bubalo JS, McCune JS. Optimal prevention of seizures induced by high-dose busulfan. Pharmaco- therapy 2008;28:1502-10.

26. Kato K, Harada M. Present status in hematopoietic stem cell transplantation: peripheral blood stem cell transplantation. Nihon Naika Gakkai Zasshi 2005;94:1281-6.

27. Fischer M, Schmutzhard E. Posterior reversible encephalopathy syndrome. J Neurol 2017;264:1608-16.

28. Fugate JE, Claassen DO, Cloft HJ, Kallmes DF, Kozak OS, Rabinstein AA. Posterior reversible encephalopathy syndrome: associated clinical and radiologic findings. Mayo Clin Proc 2010;85:427-32.

29. Pavlakis SG, Frank Y, Chusid R. Hypertensive encephalopathy, reversible occipitoparietal encephalopathy, or reversible posterior leukoencephalopathy: three names for an old syndrome. J Child Neurol 1999;14:277-81.

30. Sostak P, Padovan CS, Yousry TA, Ledderose G, Kolb HJ, Straube A. Prospective evaluation of neurological complications after allogeneic bone marrow transplantation. Neurology 2003;60:842-8.

31. McKinney AM, Short J, Truwit CL, McKinney ZJ, Kozak OS, SantaCruz KS, et al. Posterior reversible encephalopathy syndrome: incidence of atypical regions of involvement and imaging findings. AJR Am J Roentgenol 2007;189:904-12.

32. Fugate JE, Rabinstein AA. Posterior reversible encephalopathy syndrome: clinical and radiological manifestations, pathophysiology, and outstanding questions. Lancet Neurol 2015;14:91425.

33. Antunes NL. Seizures in children with systemic cancer. Pediatr Neurol 2003;28:190-3.

34. Cordelli DM, Masetti R, Zama D, Gueraldi D, Rondelli R, Cottone $\mathrm{C}$, et al. Etiology, characteristics and outcome of seizures after pediatric hematopoietic stem cell transplantation. Seizure 2014;23:140-5.

35. Uckan D, Cetin M, Yigitkanli I, Tezcan I, Tuncer M, Karasimav $\mathrm{D}$, et al. Life-threatening neurological complications after bone marrow transplantation in children. Bone Marrow Transplant 2005;35:71-6.

36. Iguchi A, Kobayashi R, Yoshida M, Kaneda M, Watanabe N, Cho Y, et al. Neurological complications after stem cell transplantation in childhood. Bone Marrow Transplant 1999;24: 647-52.

37. Sullivan KM, Agura E, Anasetti C, Appelbaum F, Badger C, Bearman $S$, et al. Chronic graft-versus-host disease and other late complications of bone marrow transplantation. Semin $\mathrm{He}-$ matol 1991;28:250-9.

38. Padovan CS, Gerbitz A, Sostak P, Holler E, Ferrara JL, Bise K, et al. Cerebral involvement in graft-versus-host disease after murine bone marrow transplantation. Neurology 2001;56:1106-8. 
39. Padovan CS, Bise K, Hahn J, Sostak P, Holler E, Kolb HJ, et al. Angiitis of the central nervous system after allogeneic bone marrow transplantation? Stroke 1999;30:1651-6. 